\title{
ASPECTOS ÉTICOS E LEGAIS DAS ANOTAÇÕES DE ENFERMAGEM NOS PROCEDIMENTOS DE DOAÇÃO DE ÓRGÃOS PARA TRANSPLANTES'
}

\section{ETHICAL AND LEGAL ASPECTS OF THE NURSING RECORDS OF ORGAN DONORS FOR TRANSPLANT}

\author{
Maria Célia Barcelos Dalri* \\ Lidia Aparecida Rossi** \\ Emilia Campos de Carvalho***
}

DALRI. M.C.B. et al. Aspectos éticos e legais das anotacos de er lermagem nos procedimentos de doactao de órgãos para transplantes Rev.Esc.Enf.USP. v.33, n.3, p. 224-30, set. 1999.

\begin{abstract}
RESUMO
O objetivo deste estudo foi verificar os registros de enfermagem de pacientes doadores de órgãos quanto aos aspectos cticos e legais. Foram analisados os registros de enfermagem de 12 prontuários de pacientes doadores de órgãos internados em $11 \mathrm{~m}$ Hospilal Universitario do interior do estado de São Paulo, no periodo de janeiro de 1992 a agosto de 1996. Foi identificada a informagão quanto ao consemtimento para doaço de órgäos nos registros de enfermagem 'm 16,7\% dos prontuários. Observamos, em $91.7 \%$ dos prontuarios, falla de dala, de assinaturas, ou presenca de rasuras nos regislros de enfermagem.
\end{abstract}

INI'TERMOS: Registros de enfermagem. Ética. Doadores de órgaos.

\begin{abstract}
The objective of this sludy was to verify the elhical and legal aspects concerning the documentation of nursing practice in the organ donor's records. The reconds of the 12 organ donors admilled in a Brazilian. University Hospital, from .January/1992 to angust/1996 were analysed. The donor consent was reporled by murses in $16.7 \%$ of the records. Defects that preclude legal value for the charling such as missing dale or signalure, erasure were found in $91,7 \%$ of the records.
\end{abstract}

UNITERMS: Nursing records. Ethics. Tissue donors.

\section{INTRODUÇÃO}

Com o avanço da tecnologia a enfermagem tem enfrentado mudanças que envolvem diferentes aspectos da sua pratica. Os enfermeiros, que atuam em unidades de atendimento de urgencia principalmente, têm se deparado com o paciente que a partir lo uma situação traumática torna-se doador de órgãos.

Nesse contexto, o nosso alvo de atenção b o conteúde das anotações de enfermagem. Assim. temos procurado por padrões que possam orientar os profissionais de enfermagem na realizaçio dos registros de enformagem nessas circunstâncias. Neste sentido, e importante lembrar que os registros do onformagem retratam a pratica desses profissionais e portanto esses padrões devem ser adotados como guia para assistôncia de enfermagem a ser roalizala.

A documentação das ações de enfermagem tem se const il uido em foco de atenção de diferentes estudos (GWO\%D\%: DEL, TOGNO-ARMANASCO, 1992.). Falhas tôm sido identificadas no seu conteúdo, que nem sempre refletem a prática realizada.

\footnotetext{
- Este trabalho foi aprovado pelo Comito de Étiea e Pesquisa do llospital em estudo

* Diretora Téenica de Serviço de Cento Cirúrgico e Material Hospilal das Clinicas da Faculdade de Medicina de Ribeirão Preto

* Professora Doutora do Departamento de Enfermagem Geral e Especializala da Escola de Enfermagem de Ribeirao Preto, Universidade de Sao Paulo (EERP. USP).

*. Professora Titular do Departamento de Enfermagem Geral e Especializada ELRP. USP. Email: rizzardo@glete.eerp.usp.br
} 
HOWSE; BATLEY (1992), utilizando o método etnografico, examinaram as atitudes de onfermoiros para identificar as resistências a documentação nos prontuários dos pacientes, e os fatores extrínsecos e intrinsecos que determinam essa siluação. Os resultados desse estudo sustentam a crença comum de que a resistência na realização dos registros de enfermagem é influenciada por fatores extrínsecos. como a inflexibilidade dos sistemas de registros e a falta de tempo. Os latores intrínsecos. que emergiram como impedimentos a documentação. foram a falta de confiança nas expressooes escritas. uma tendência a sucumbir as normas referentes aos registros. e dificuldades om articular a natureza da prática de enfermagem. Sob esse aspocto e importante lembrar que se uma aç̃o não foi registrada, legalmente ela pode ser interpretada como não tendo sido realizada.

Os registros roalizados nos prontuários de pacientes são fonte inestimavel de dados e são utilizados por todos os membros da equipe de saúde. 'Tem como finalidade a comunicaç̃o de in formaçôs solve o pacien te, possibilitar o ensino, a pescauisa. a realização de auditorias e a verificação de aspectos legais (PO'TTTER : PERRY, 1989).

As anotaçōes de enfermagem podem englobar lanto o registro de procedimentos de enformagem realizados. descrição de latos, eomo dados que sĩo resultados de uma avaliação do paciente. ou seja. a evolução de enfermagem.

Algumas recomendações sobre as earacterísticas das anotações de enformagem são basicas e parecem ser conhecidas dos prolissionais de enfermagem e embora a princípio parceam obvias. necessitam ser reafirmalas. Assim. os registros devem ser descritivos. completos. objotivos. claros. assinados. legiveis e datados.

Os registros devem ser deseritivos sem interpretaçôes ou denúncias. É importante lembrar que o prontuario do paciente não of local apropriado para a realização de denúncias. mas pode ser fonte de pesquisa e verilicaços legais, assim. pode fornecer informaçoes para que uma determinada ocorrência seja julgada. Esse aspecto foi abordaclo por OGUISSO (1975) $\mathrm{em}$ seu estudo sobre o concoúdo das anotações de enfermagem enfocando os aspectos que envolviam danos aos pacientes. Quando informamos sobre um proeedimento realizado. essa informação deve realmente sor calaz de comunicar o cue aconteceu sem interpretaçoes e de forma completa. A recomendação de que a anotação seja completa implica em náo deixar margem para interpretaçoes ou chúvilas sobre as questones que podem estar rolacionalas com a siluação descrita. Sobre essa questão. OQUISSO (1975) afirma que "constitui dever do pessoal de enformagem a anotação perfeita isto o. completa. cabal. correta".
Assim. segundo a autora, a anotação deve incluir tudo o que se relacionar com o paciente.

A clarcza das anotaçoes se refere ao encadeamento das ideias que deve obedecer a uma ordom determinada. Desta forma, quando registramos o exame físico de um paciente uma das formas adotadas é a descrição dos dados obedecendo uma determinala ordem. como a orientação céfalo. caudal ou por sistomas. A objetividade da anotação implica em enfocar o assunto sem rodeios, não repetindo informações.

Como documento, esses registros somente terão valor legal se forem datados e assinados e, evidentemente, so forem legiveis e não apresentarem rasuras. Segundo OGUISSO (1975), são essas recomenclações que caracterizarão a autenticidade de um documento. Para a autora a ausência de anotaçoses ou os registros realizados de forma incompleta podem indicar uma má qualidade da assistoncia de enfermagem.

Assim, um aspecto importante da anotação é que ola ó o reflexo da prática e. desse modo, implica em consideraçốcs éticas. A ética se refere à reflexão filosolica sobre a conduta humana onde a bioética. segundo CORRESA (1995), o um neologismo que signilica ótica da vida, assim, "tudo o que é vida lhe compete".

A ética o a bioctica devem ser tratadas com igualdade, levando-se em conta as disciplinas e implicações do conhecimento e avanço científico e tecnologico. como esturlos interdisciplinares dos problemas advindos do progresso biomédico, "seja em nivel de relações individuais, institucional ou mesmo de estrutura social" (PESSINI: BARCHIFON'IAINE, 1994).

Os aspectos éticos o legais que envolvem a doação do orgãos, foco de intoresse deste estudo, foram estudados por SCHROFITER (1995), que enlocou essa guestão eom base nos princípios bioclicos: altruísmo. autonomia. beneficencia, justiça o utiliclade. Para a autora, os princípios de altruísmo o autonomia são ovidentes no processo de doação de orgños. Quando se tratar de um doador vivo, ele deverá ter autonomia oliberdade para escolher entre doar ou não o orgão e para quem doar. Essa é uma decisão autônoma, tanto quanto é um ato altruísta o benevolente. Para que essa decisão seja autônoma o importante que o doador vivo compreenda todos os riscos a que será submotido caso sua escolha seja a doação (SCHROETER, 1995).

SCHROIETER (1995) afirma também que há "uma associaçĩo bbvia entre as questões que envolvem a loação de orgãos e os princípios de beneficencia, autonomia, justiça e utilidacle". Os atos do doar orgão e o de transplantar são realizados para beneficiar indivíluos que estão criticamente doentes. 
() benefício deve incluir a melhora da saúde do receptor e o conforto e bem estar do doador (quando (loador vivo) ou da família do doador. A utilidade inclui os possíveis benefícios e as conseqüências negativas que poderão ser de ordem médica, psicológica e financeira. As considerações sobre a justiça requerem que os pacientes receptores sejam avaliados individualmente sem considerar questões de gênero. raça e slakus sócio-econômico.

Segundo a autora, a aplicação desses princípios é integral quando se trata de doações de orgãos. e é responsabilidade dos médicos. dos onfermeiros. das comissões de etica e das orcanizações que atuam na procura do orgãos para transplantes.

Quando iniciamos este estudo. com rolação à doação de orgãos. a legislação brasileira exigia o consentimento de familiares para retirada de orgãos apos a morte encefálica. A partir de 1" de jan eiro de 1997 a Lei 9434 . que dispõem sobre a remocião de oroãos. tecidos e partes do corpo humano para lins de transplante e tratamento. no Capitulo 1 . (BRASIL, 1997). estabelece que:

Arl. 4. "Salvo manifeslacão de vonlade em contrário, nos termos dessa lei, presume-se aulorizada a doascão de órgãos ou parles do corpo em lecidos, órgãos ou parles do corpo humano, para finalidade de Iransplante ou terapêtulica post mortem".

Parágra/o l. "A expressĩo não doador de órgãos e lecidos deverá ser grauda de forma indelével e invioliwel na Carleira. de Idenlidade Civil e na Carleira Nacional de llabililascão da pessoa que optar por essa condicão".

Entretanto. apesar das modificaçoes na legislação. na prática do hospital cm estuclo as rotinas ainda não foram alteradas e, deste modo, para retirada de orgãos para transplante apos a morte encefálica. continua sendo solicilado o consentimento de familiares destes pacientes.

É importante lembrar que para a realização desso procedimento o paciente deve estar em estado comprovado de morte encefálica. Sobre essa questão. no Brasil. a Lei n. 9434. no Capítulo II (BRASIL. 1997). estabelece que:

Art. 3. A relirada post mortem de lecidos, orgãos ou parles do corpo humano destinados a lransplanle ou lratamento deverá ser precedida de diagnostico de morle encefilica, conslalada e regislrada por dois médicos näo parlicipanles das equipes de remocão e transplante, mediante a Hulilização de crilérios clínicos e lecnológicos definidos por resolução do Conselho Federal de Medicina.

Considerando esta resolução, o CONSELHO FEDERAL, DF: MEDICINA (CFM, 1997) estabelece que:
"os parâmetros clinicos a serem observados para conslatacão de morte encefálica são: coma aperceptivo com atsência de alividade motora supra- espinal e apnéia. (...) Os exames complementares a serem observados para constalacão da morte encefálica deverão demonstrar de forma inequivoca: a) ausência de alividade elétrica cerebral ou, b) ausência de alividade metabólica cerebral ou, c) ausência de perfusão sangüinea cerebral."

Os incervalos mínimos entre as duas avaliaçoons clínicas e a indicação desses exames devem estar de acordo com a faixa etária (CONSELIHO FEDERAI. DE MEDICINA, 1997).

Entendemos que os registros de enfermagem devem conter informaçoes que estejam em consonância com os aspectos mencionados neste estudo. considerando as resolucões apresentadas anteriormente e as características de uma anotação para (jue possa subsidiar investigacooes e ainda ter valor legal inquestionável. Nesse aspecto, uma questão que emerge é: como. o que e quando devemos registrar as acoes de enformagem que se referem às siluacoos do doaç̃̃o de orgãos após morte encefálica? Assim, decidimos realizar esse estudo, com a finalidade de estabelecer recomendações fundamentadas em aspectos éticos e legais para a elaboração da documentação de onfermagem em situacóes de doaç̃̃o de orgãos para transplante após morte encefálica, enfocando os períodos pré, trans e pós operalório. Para tanto, inicialmente o objetivo deste estudo foi: vorificar os registros de enfermagem de pacientes doatores de orgãos nos períodos pré, trans opos-operatórios quanto aos aspectos éticos e legais.

\section{METODOLOGIA}

O estudo foi desonvolvido a partir de um levantamento retrospectivo. pelos pescluisadores, dos rogist ros do enfermagem de pacientes doadores de orgãos nos períolos pré, trans e pós-operatório 
internados em um Hospital Universitário do interior do estado de São Paulo *, no periodo de janciro de 1992 a agosto de 1996. A relação dos prontuários consultados foi elaborada a partir dos registros de procedimentos do centro cirúrgico da Unidade. Foram identificados 20 doadores de organos nesse período e foram analisados todos os prontuários disponiveis no Servico de Arquivo Médico e Eslatística do hospital em estudo, tolalizando 12 prontuários.

Para análise dos daclos foi utilizado um roteiro. construíclo para essa linalidade. compreendendo a seguinte estrutura:

- informações relativas ao periodo préoperatório: registro de avaliação do pacionte compatível com o estado do pacionte (morte encefálica); registros, realizados pelo enfermeiro. de informaçoes sobre o consentimento da família e registros de encaminhamento do paciente para o centro cirúrgico com informações sobre seu estado;

- informaçôes relativas ao periodo transoperatório: registros de recepção do paciente no centro cirúrgico com avaliação completa do seu estado, da posição do paciente na mesa cirúrgica. da instalação de equipamentos. do inicio o lermino dos procedimentos anestésicos e cirú rgicos propostos e realizados. de intercorrências, das eondiçós de encaminhamento e destino imediato do órão. conforme propoem FISCHBAH (1991) ; GRANI)USKY (1992):

informações relativas ao periodo pósoperatório: regist ros referentes às condicones gerais do paciente. especificando a parada de sinais vitais. e registros sobre o preparo o destino do corpo:

caracteristicas das anotações: completas. incompletas (em caso de anotação incompleta. essas foram especificalas), descritivas, objetivas. claras. autenticas (foram especificadas). lissas caracteristicas foram avaliadas com baso nos conceitos estabelecidos por OGUISSO (1975), apresentados anteriormente.

\section{RESULTADOS E DISCUSSÃO}

No periodo pré. trans e pos-operatório. todas as informaçoes analisadas foram caracterizadas como descritivas e objotivas. Entretanto. nos registros do enfermagem no período transoperatório. em $16.7 \%$ dos prontuários olservamos que as informações sobre a cirurgia roalizala estavam incompletas. Encontramos uma relerencia à retirada de orgãos, em um prontuário, mas esses não estavam especilicados pela enformagem. Esso tipo de anotação não fornece subsílios para um julgamento preciso do ocorrido. Embora a retirada de orgãos soja realizada pela equipe médica, a enfermagom é co-responsável por sua realização e deve se reportar aos fatos de forma completa em seu registros, deve estar atenta ao consentimento para realização do procedimento e ao tipo de procedimento realizado.

Quanto ao consentimento para doação de órãos pelos familiares dos pacientes, $16,7 \%$ dos prontuários continham essa informação no período próoperalório, registrada na evolução de enformagem e estes registros loram realizados pelo enfermeiro. Tamberm não foi identificado o ofício de consentimento em $33 \%$ dos prontuários, embora rolerência a sua cxistência estivesse registrada por outros prolissionais não pertencentes à equipe de enfermagem. Sobre essa questão, Cóligo de Ética dos Profissionais de Enfermagem (COREN - SP, 1996) esclarece no Capitulo $V$, que não é permitido aos profissionais de enfermagem:

Artigo 4.1 - "parlicipar de tratamento sem o consentimento do cliente ou do represenlanle legal, exceto em iminente risco de vida"

Arligo 66 - "colaborar, direla ou indirelamente com outros profissionais de saúde, no descumprimento da legislascono referente ao transplante de órgãos, lecidos esterilizacão ou fecundaçoo artificial."

Como já mencionamos, a lei atual, que dispõe solbre a remoção do brgãos, tecidos e partes do corpo humano para fins de transplante, modifica esta sit uação (quando estabelece que a pessoa não doadora do ordãos devo so reportar a essa condição em seus documentos. impondo a necessidacle da verificação, na Cartoira de Identidado Civil e na Carteira Nacional (lo Habilitação, quanto a opção realizada pela pessoa. A partir de $1^{0}$ de janeiro, quando a lei começou a vigorar, esse assunto passou a ser tema constante na imprensa brasileira. Através deste debate, podemos apreender que a maioria dos médicos entende que a obtenção de consentimento dos familiares de pessoas $\mathrm{cm}$ morte encofálica deve continuar sendo condição para a rotirada de Greños para transplante, conforme reportagens publicalos por NANSO, (1998) ; MAR'IINS, (1998) e II:IIIN. (1998).

De qualquer forma, é necessário que o Hospital em estudo, discuta essa questão e avalie as rotinas rolacionadas com a remoção de orgãos, teciclos e partes do corpo humano para fins de transplante.

No período trans-operatório as anotações analisadlas foram consideradas incompletas em $100 \%$ dos casos. No Centro Cirúrgico. os registros refletem uma preocupação com a documentação da chegada 
(o) paciente. mas nem sempre incluem uma avaliação de seu estado. Outras informaçoos são recistradas o parecem obedecer a uma rotina. como o início o término da cirurgia e da anestesia e a colocação da p) laca do bisturi. Entretanto. não encontramos informações sobre a posição do paciente na mesa cirúrgica ou sobre a instalação de equipamontos. Essas ações e os outros procedimentos que podem ser realizados com o paciente durante o alo anestésico e cirúrgico e que, de alguma forma. envolvem a participação da en fermagem, devem ser documentados, já que podem acarretar alterações na estrutura corporal do paciente.

O fato do paciente se encontrar em morte encefálica não exime o profissional de enfermagem (lo dever de atuar de forma tal que preserve a integridade do paciente. Neste sentido. os registros do enfermagem devem retratar essa proocupação. Lembramos que o Art. 33 do Cóligo de Ética dos Profissionais de Enfermagem (COREN - SP. 1996) estabelece como dever dos profissionais de enfermagem "respeitar o ser humano $\mathrm{cm}$ siluacioes de morte e pos morte".

lim 50\% dos prontuários não foram encontraclos regist ros de avaliação pela en fermagem após a cirurgia. informan do sobre a parada dos sinais vitais, ou sobre o estado do pacionte. Apos o término da cirurgia a informacĩo seguinte o 0 encaminhamento do paciente para o morgue. A enfermagem deveria nesse momento registrar. na folha de evolução de enfermagem, uma avaliação do paciente reportando-se ao seu estado de forma descritiva. Encontramos um registro em que o profissional de enfermagem informa que a morte encefálica foi constatada pelo médico após a realização do a to cirúrgico para retirada dos orgãos, entretanto no prontuário há registros dos exames realizados e da constatação da morte encefálica anterior à cirurgia.

Muitas anotaçoes polem ser realizadas ingenuamente. som que o profissional tenha consciência do significado de seu conteúdo ou por desconhecimento e muitas ve\%es não refletem a veracidade dos fatos. entretanto. podem ter implicações legais sérias. SHIMID'l: OGUISSO (1986) alertam que os profissionais de en fermagem deveriam estar atentos quanto ao conteúdo das anotações de enformagem "para não serem envolvidos em questões judiciais". mas so isso acontecer não poderão eximir-se da responsabilidade conferida pela profissão. Consideramos importante lembrar o Art. 20, do Codigo de Ética dos Profissionais de Enfermagem (COREN - SP, 1996) que considera dever desses profissionais "responsabilizar-se por falta cometida em suas atividades profissionais, independente de ter sido praticada individualmente ou em equjpe".
As informações registradas pela enfermagem quanto ao encaminhamento do orgão foram obscrvalas em $16,7 \%$ dos prontuários, sendo que $8.3 \%$ especificaram o local para onde o brgão foi encaminhado. Segundo HARASYKO (1989), os rins retirados do doadores cadáveres devem ser transplantalos dentro de 24 a 36 horas apos a retirala, o com o acondicionamento e perfusão adequados poderño ser utilizados até apos 72 horas. O Grgão rotirado tom o valor de uma vida, e deve merecer todo cuiclaclo. Assim. e muito importante o registro dos procedimentos realizados para o seu acondicionamento e transporte.

Um outroponto importante é o destino imediato do órgão retiralo, que deverá ser registrado. A legislação não se reporta a esse respeito mas no Capítulo IV, parece delegar o controle do destino do oreño às contrais de notificação, capitação e distribuiç̃o (BRASIL, 1997), quando diz que:

\section{Art. 13 "É obrigalório, para todos os estabelecimentos de saude, notificar às cemlrais de notificacão, caplacão e distribuicano de orgũos da unidade federada onde ocorrer o diagnóstico de morle encefálica feilo em pacientes por eles alendidos".}

Neste sentido, lembramos os princípio ético de justica que requer (jue os pacientes receptores sejam avaliados individualmente sem considerar questões do gônero, raça e slatus socio-econômico e de bencliconcia. Os enfermoiros devem estar atentos quanto ao encaminhamento imediato do orgão quanto ao registro dessa informação no prontuário para não serem envolvidos em situações que possam ter implicações legais.

Olsservamos nas anotaçoes de onlermagem em 91.7\% clos prontuários situaçóes como falta de data o de assinaturas. o presenca de rasuras. Essas situaçoes invalidam o valor legal de um documento.

Considerando que o prontuário do paciente é documento que tem valor legal. é importante enfocar alguns aspectos que podem ser caracterizados a partir dos registros de enfermagem. SHIMID'T: OGUISSO (1986), analisando o termo rosponsabilidade nos aspectos jurídico. civil e penal. o elico prolissional e as implicaçoes que envolvem o exercicio legal da enfermagem, consideram que são medidas legais de culpa: imprudência, negligência c impericia. Segundo NORONHA (1968), a negligrencia está caracterizada (quando podendo agir (lo uma outra maneira. por indolência ou preguiça mental, não age ou se comporta de modo diverso: a imprudência consiste em agir com precipitação, insensalez ou inconsideração, sem a cautela necessária e sem atender às circunstâncias ou à 
razão: e a impericia consiste na incapacidade ou laula de conhecimento ou habilitação para o exercício de um determinado mister. Assim. um exemplo e o regist ro de enfermagem que se refere à constataç̃o de um obito: "Foi constatado obito as 20:00 horas": legalmente os profissionais de enfermagem não estão habilitados para realizar essa constatação. uma aç̃o desse tipo pode ser caracterizada como exercício ilegal da profissão. Outro exemplo é a documentação de um problema apresentado pelo paciente. sem a intervencĩo pertinente, o que pode ser caracierizado como negligêneia.

OCUISSO (1975) tambem se rejorla a falsidade ideológica que seria a omissão de informaçôes e dos registros de dados incorretos ou incompletos ou incxistentes e a assinat ura declarando a realização de uma ação que na verdade foi realizada por outra pessoa. O Artigo 64 do Capílulo V do Cooligo de lílica dos Profissionais de Enfermagem (COREN - SP', 1996) esclarece que 6 proibido aos profissionais de enfermagrem "assinar as açoes de Enfermagem gue não executou. bem como permitir que outro prolissional assine as que executou".

\section{CONSIDERAÇÕES FINAIS E RECOMENDAÇÕES}

Ei importante ressaltar que, muitas vezes, o registro de enfermagem e realizado de forma automática e pode não retratar a realidade eompletamente. mas de qualquer forma o o rotrato do trabalho do profissional que o assina e reflete a qualidade da prática

Os prontuários de pacientes são fontes de informação para pesquisa, ensino. continuidade da assistência ao paciente vorificaçoos quanto a questões legais e éticass e avaliação da qualidacle do cuidado. Assim. recomendamos que os profissionalis de enfermagem estejam atentos quanto a alguns pontos relacionados as anotaçoes de enfermagem:

- as anotaçoos no prontuario dovem ser completas incluindo. sogundo FISCHBAHI (199) : GR.ANDUSKY' (1992) a AORN (1994):

- avaliaçoos descritivas do estado do paciente imediatamente antes e após a realizaça do ato cirúrgico informando soloro seu estado geral e especificando sobro o nivel de consciência. o lipo do respiração apresentada. a condição das pupilas. as respostas a estímulos dolorosos e ao eomando verbal. e condiçoes da pole:

- informacoos sobre o encaminhamento do paciente ao eentro cirúrgico especifieando tipo de transporte, posição do paciente o assistôncia realizada durante o trajeto:
- informações sobre o destino de documentos, perlonces o próteses rotiradas dos pacientes;

- medicações administradas ou preparadas pelo pessoal de enformagem;

- posicionamento do paciente na mesa cirúrgica, incluindo os equipamentos utilizados para suporte e contenç̃̃o:

- tipo o localização de equipamentos instalados no paciente, incluindo almofadas, coxins, eletrodos, placas de bisturis e outros equipamentos;

- procedimentos anestésicos e cirúrgicos realizalos com o paciente, devem ser registrados com clareya especificando o tipo de procedimento roalizarlo. in ício o tórmino. orgãos ou peças retiradas. as pessoas que participaram dos cuidados intraoperatórios e a lonte da informação:

- condiçôes de encaminhamento e o destino imodiato do peças cirúrgicas ou de orgãos retirados para transplantes e do proprio corpo do paciente dovem ser ospecificados nos registros de enformagem;

- informacões sobre a obtenção do consentimento informado. Considerando a conduta adotada atualmente na instituição em estudo, o consentimento (la família para a realização de procedimentos cirúrgicos para doação de órgão deve ser solicitado pelo médico ou pessoa responsável. uma via desse consentimento deve estar anexada ao prontuário e a enformagem deve se reportar a cle em seus registros. Entretanto, considerando a Lei 94:34 (BRASIL. 199T), sugerimos a realização de uma avaliação da conduta atual;

- a constatação da morte encefálica não compete aos profissionais de enfermagem, mas eles devem estar atentos quanto a sua realização e quanto aos resultados. Qualquer procedimento realizado com o paciente, que envolve a participação da enfermagem deverá ser registrado por esse profissional. em respeito ao Artigo 20, Capítulo III, (o) Cóligo de Ética dos Profissionais de Enfermagem (COREN - SP. 1996), (jue considera como responsabilidade dos profissionais de enfermagem "responsabilizar-se por falta cometicla em suas atividades profissionais, independente de ter sido praticada individualmente ou em equipe". Assim, cmbora algumas atividades não sejam de competencia da enfermagem, ela é co-responsável pola sua realização por isso deve documentar a sua ocorrência.

- as anotações devem ser descritivas, objetivas, claras e autênticas:

- o profissional de onformagem deverá estar atento para não registrar interpretações ou fazer julgamentos, não rasurar ou deixar espaços em braneo na folha de anotação. para a identificação do 
paciente. para o registro da data. da hora e da sua assinatura. acompanhada da função e ainda. segundo o Artigo 76 do Cóligo de Ética dos Prolissionais de Enfermagem (COREN, 1996). do número de inscrição do Conselho Regional de Enfermagem:

As anotações de enfermagem devem retratar a prática funclamentada nos princípios éticos e legais. Para que isso seja alcançado, a educação continuada nos serviços de enfermagem o uma estrategia importante que pole promover a alualização dos profissionais e a melhora da qualidade da assistência.

\section{REFERÊNCIAS BIBLIOGRÁFICAS.}

1. ASSOCIATION OF OPERATION ROOM NURSES MORN standards and recommended prictices for perioperative nursing. Denver. 1994.

2. BRASlL. Leis. . Lei $n 9434$ de 04 de fevereiro de 1997 . Dispoe sobre a remoça de órgaos, tecidos e partes do corpo humano para fins de transplante e tratamento. Diario Oficial da Uniño, Brasília, 05 fev. 1997. Secão 1. p. 2191.3.

3. CONSELITO FEDERAI, DE MEDICINA Resolụno n. 1.180 de 8 cle agosto de 1997. Diário Oficial da União, 21 ago 1997. p. 18227.8

4. CONSEI.HO REGIONAI, DE ENFERMAGEM Principais legislaçoes para o exereício da enfermagem. Să Paulo. 1096.

5. CorreiA. F. de A. Alguns desafios atuais da bioética. RER. v.55, p.65-86, 1995 .

6. FISCHBACH. F. T. Documenting care: communication. the nursing process and documentation standards. Philadelphia. Davis. 1991.
7. GR.ANDUSliY, R. J. Perioperative documentation In: SPRY, C. The manual of operating room management: an administrative and patient care resource. Maryland, Aspen, 1992.

8. GWOZD\%. D. 'T.: DEI, TOGNO.ARMNASCO. V. Streamlining patient care documentation. J. Nurs. Adm., v.22, n.5, p. 35 . 9.1992 .

9. IIAHN. S. "Familia tem que autorizar" Folha de São Paulo, São Pauto, 03 jan. 1998, p.f.-3.4.

10. IIARASYKO. C. Kidnoy transplantation. Nurs. Clin. North Am.. v. 2.1. n. 4. p. $851 \cdot 63.1989$.

11. MOWSLE L: B.MLFY, d. Resistance to documentation - a nursing research issue. J. Nurs. Stud.. v.29, n.4, p.371-80, 1992.

12. MANSO, 13. P. Doạ̧o dilícil. Veja. n. 1. p. 43. jan. 1998.

13. M.ARTINS, 1. Entidade propoe mudanęas a Ministério Folha de Sĩo Paulo. Sao Paulo. 08 jan.1998, p.f.-3.9.

1. NORONIA. F. M. Direito penal, parte especial 16.ed., Sao Paulo. Saraiva. 1980.

15. OGUISSO. 'l' Os aspectos Iegais da anotacão de enfermatgem no prontuário do paciente. São Paulo. 1975. T'ese (l.ivre Docencia). Escola de Enfermagem Ana Néri. Universidade Federal do Rio de Janeiro.

16. POI"lER, P.A. : PERRY. A.G. Fundamental of nursing. Saint. louis. Mosby, 1989.

17. PISSSINI. 1.: BARCHIPONTAINE. C. de P. de Problemas atuais de bioćtica. 2 ed.. Sao Paulo. Loyola. 1994.

18. SIIIMIDT. M. J : OGUISSO. T. O exercicio da enfermagem sob o enfoque das normas penais e éticas. Rev. Paul. Enf., v. 6. 11. 1, 1. 10-2. 1986 .

19. SCHROFETER, K. The ethies of organ donation. Todays OR Nurse, v. 17, n. 1. p. 8.12, 1995 